\section{Establishment of an intermediate care ward for babies and mothers}

Sir,

Dear and McLain have shown clearly how the establishment of an intermediate care ward reduced the admission rate to their neonatal unit. ${ }^{1}$ Although such a ward may be useful in some hospitals, a similar admission rate has been achieved at this hospital by different means.

In 1979 the admission rate to the neonatal unit was $15.7 \%$. Seven years later it had fallen to $5 \cdot 2 \%$ of babies delivered at the hospital. This was achieved by nursing all babies who fulfilled the criteria described by Dear and McLain for admission to their transitional ward on the postnatal wards. Some babies weighing $<1700 \mathrm{~g}$ were also nursed with their mothers on the postnatal wards, but all babies with respiratory distress or who required intravenous fluid replacement were admitted to the neonatal unit.

The policy of nursing babies with special needs on the postnatal wards was effected by allowing all midwives of staff nurse grade and those newly appointed as sisters to spend six month periods on rotation to the neonatal unit. Thus expertise and familiarity with the problems of small babies were spread through the whole hospital.

This policy of rotating midwifery staff had two additional advantages. Firstly, staff from the lying in wards were able to help out in the neonatal unit when required and, secondly, because all nursing staff had personal experience of the problems of the neonatal unit, this maternity hospital functioned as an integrated unit rather than the needs of special babies being separated from others.

\section{Reference}

1 Dear PRF, McLain BI. Establishment of an intermediate care ward for babies and mothers. Arch Dis Child 1987;62:597-600.

A M Weindling and $\mathrm{R}$ W I Cooke Regional Neonatal Intensive Care Unit, Liverpool Maternity Hospital, Liverpool $L 77 B N$

\section{Preterm blood counts vary with sampling site}

Sir,

Thurlbeck and McIntosh have recently studied the changes in neutrophil counts at different sampling sites. ${ }^{1}$ In their study, $0.5 \mathrm{ml}$ of blood was drawn through an umbilical artery catheter, and then $0.5 \mathrm{ml}$ was obtained by free flowing heel prick $(n=13)$ or peripheral venepuncture $(n=21)$. The average difference between the capillary compared with the arterial neutrophil counts was +1800 cells $/ \mathrm{mm}$. The difference in neutrophil counts between venous and arterial blood samples was not significant. They therefore concluded that it is important to sample from a vein or artery, rather than a capillary vessel, to avoid error in interpretation.

The cause for the increased neutrophil count in capillary blood is not clear from this study. One important possibility is that a rise in the blood neutrophil count during the prolonged capillary sampling may occur, induced by the pain it causes. This may also explain the higher variability found in the neutrophil counts in capillary blood.

A significant rise in white cell count from the marginal granulocyte pool may follow exercise or injection of epinephrine, and occurs with remarkable speed. ${ }^{2}$ Counts of 35000 cells $/ \mathrm{mm}$ have been recorded after a $400 \mathrm{~m}$ run completed in one minute.

We have recently studied the white cell count in venous blood before and 10 minutes after lumbar puncture in 20 neonates. There was a significant $(\mathrm{p}<0.001)$ increase in the white cell count from a mean (SD) of $9.6(3.4) \times 10^{9} / 1$ before, to $13 \cdot 4(3 \cdot 7) \times 10^{9} / \mathrm{l}$ after the procedure, caused by a rise in the neutrophils and lymphocytes. There is a reason to believe, therefore, that the higher neutrophil counts found in the samples from capillary blood were associated with the order of sampling used in the study and not necessarily with the site itself. ${ }^{1}$ If that is the case, venous and arterial sites will also fail to give reliable counts if samples are taken during or after stressful events. This question could have been answered if a third blood sample had been taken through the umbilical artery catheter after the capillary sampling, or if the order of sampling had been randomised.

\section{References}

1 Thurlbeck SM, McIntosh N. Preterm blood counts vary with sampling site. Arch Dis Child 1987;62:74-5.

2 Weitzman M. Diagnostic utility of white blood cells and differential cell counts. Am J Dis Child 1975;123:1183-9.

Mordechal Shohat Department of Pediatrics/Genetics, Cedars-Sinai Medical Center, Los Angeles, CA 90048, USA

Dr Thurlbeck comments:

Dr Shohat's interesting letter raises points which would have been discussed more fully had space allowed. Arterial sampling, which does not disturb the infant, was performed first because of the effect of painful procedures on the neutrophil count in term infants which has already been described. ${ }^{1}$ This could well be a reason for the difference which we observed but it is of note that venous sampling, which is presumably painful too, had no effect. It is inaccurate to describe the observed difference as being due to the order of sampling as such, if the higher neutrophil counts with capillary sampling are, as Dr Shohat suggests, induced by demargination of granulocytes because of release of adrenaline caused by the pain of the sampling procedure itself.

Ethical considerations precluded capillary sampling both before and after arterial sampling, and a direct comparison 
of venous and capillary sampling, but it would have been interesting to have had two groups, one in which capillary sampling preceded arterial sampling and one in which it was done afterwards. Our data did not show a variation in the white cell count, and I wonder what mechanism Dr Shohat proposes for his observed rise during and after lumbar puncture.

These points emphasise the difficulties in establishing a reference range of white blood count values for infants, particularly preterm infants, and in interpreting results by comparing them with published ranges. Application of the International Committee for Standardisation in Haematology guidelines for the standardisation of blood specimen collection procedures for reference values is obviously impractical, but it is clear that the method of sampling does affect the results obtained. Many of the published ranges are based almost entirely on capillary sampling so that arterial sampling, which is commonly done in these intensively monitored infants, may lead to a diagnosis of neutropenia. Conversely, as Dr Shohat points out, a painful procedure performed shortly before sampling might cause a neutrophilia equivalent to that found in older children and adults after exercise.

\section{Reference}

' Christensen RD, Rothstein G. Pitfalls in the interpretation of leukocyte counts of newborn infants. Am J Clin Pathol 1978;72:608-11.

\section{The metabolic load of stored blood. Implications for major transfusions in infants}

Sir,

In a recent article Ratcliffe $e t$ al ${ }^{1}$ described the changes in plasma osmolality, electrolyte balance, and metabolic substrates that can occur during storage of blood. These changes, an increase in osmolality, potassium, and lactate concentrations, and a decrease in sodium concentration, were ascribed to alterations in red cell permeability and continuing metabolism during storage. Infusion of large amounts of such stored blood may be harmful to the sick infant and may, for instance, result in severe hyperkalaemia. ${ }^{2}$

Interestingly, storage of fresh frozen plasma (FFP) can also produce solute concentration gradients in the infusion bags. We describe (table) the osmolality and solute concentrations incidentally measured at the surface and at the bottom of a bag containing 'unshaken' thawed plasma. To confirm this finding, we stored FFP in five $20 \mathrm{ml}$ glass tubes and subsequently thawed the samples at room temperature without shaking. The following mean (SD) plasma osmolality and sodium concentrations were recorded: 237 (5) $\mathrm{mOsm} / \mathrm{kg}$ and $33(5) \mathrm{mmol} / \mathrm{l}$ at the surface, and $425(18) \mathrm{mOsm} / \mathrm{kg}$ and $199 \mathrm{mmol} / \mathrm{l}$ at the bottom. Thorough mixing of the plasma resulted in homogenous concentrations of $321(5) \mathrm{mOsm} / \mathrm{kg}$ and $173 \mathrm{mmol} / \mathrm{l}$.

The differences in osmolality and concentrations in a cell free solution probably occur during freezing, which starts at the surface, and the free water is frozen first. We
Table Osmolality and electrolyte concentrations from surface and bottom of unit of unmixed thawed plasma

\begin{tabular}{lcc}
\hline Measurement & Surface & Bottom \\
\hline Osmolality $(\mathrm{mOsm} / \mathrm{kg})$ & 237 & 679 \\
Sodium $(\mathrm{mmol} / \mathrm{l})$ & 127 & 277 \\
Potassium $(\mathrm{mmol} / \mathrm{l})$ & $2 \cdot 6$ & $5 \cdot 2$ \\
Chloride $(\mathrm{mmol} / \mathrm{l})$ & 57 & 92 \\
Glucose $(\mathrm{mmol} / \mathrm{l})$ & 21 & $40 \cdot 7$ \\
Creatinine $(\mu \mathrm{mol} / \mathrm{l})$ & 50 & 100 \\
Protein $(\mathrm{g} / \mathrm{l})$ & 43 & 114 \\
\hline
\end{tabular}

conclude that the infusion of large amounts of unshaken thawed plasma could harm a sick neonate, and that this phenomenon could affect the accuracy of chemical analysis of samples of thawed plasma.

J B Gouyon

O GRIGORAS

J P GUIGNARD

Service de Pédiatrie,

Centre Hospitalier Universitaire,

Vaudois, 1011 Lausanne, Switzerland

\section{References}

1 Ratcliffe JM, Elliott MJ, Wyse RKH, et al. The metabolic load of stored blood. Implications for major transfusions in infants. Arch Dis Child 1986;61:1208-14.

2 Blanchette VS, Gray E, Hardic MJ, et al. Hyperkalemia after neonatal exchange transfusion: risk eleminated by washing red cell concentrates. J Pediatr 1984;105:321-4.

\section{Endotracheal resuscitation of preterm infants at birth}

Sir,

The meticulous studies into the mechanics of neonatal resuscitation carried out by Professor Milner and his colleagues over the last few years provide a unique and valuable body of information. I would, however, like to clarify certain points relating to the methodology and interpretation of their most recent work. 'In particular, how might the flow resistance of the resuscitation equipment affect the efficacy of resuscitation? The authors do not state the flow rate into their resuscitation circuit. The fact that their pneumotachograph was linear to $15 \mathrm{l} /$ minute implies that an inspiratory flow rate up to this value could be provided for.

Careful analysis of figure 1 would suggest that the effective inspiratory flow resistance of the resuscitation circuit was very high. In the figure, the 'inspiration response' of the baby caused a peak inspiratory flow rate of $5 \mathrm{l} /$ minute $(0.08 \mathrm{l} / \mathrm{second})$. This was achieved only by reducing the pressure at the endotracheal tube to $-8 \mathrm{~cm}$ $\mathrm{H}_{2} \mathrm{O}$. Thus the apparatus resistance (resistance pressure/ flow) was at least $100 \mathrm{~cm} \mathrm{H}_{2} \mathrm{O} / \mathrm{l} / \mathrm{second}$, compared with the intrinsic resistance of an intubated preterm baby of roughly $200 \mathrm{~cm} \mathrm{H}_{2} \mathrm{O} / \mathrm{l} / \mathrm{second}$. $^{2}$ Could this be part of the explanation for the very small tidal volumes achieved?

Finally, figure 3 needs further explanation. In it a 